\title{
Evaluation of Antibacterial Effectiveness of Desensitizers against Oral Bacteria
}

Ismet Duran ${ }^{a}$

Abdulkadir Sengun ${ }^{b}$

Hasan Huseyin Hadimlic

Mustafa Ulkerd

\section{ABSTRACT}

Objectives: Desensitizers contribute to better clinical results by reducing the rate of cervical dentin sensitivity. However, information on their antibacterial effect is limited. This study examined the antibacterial activities of a triclosan containing (Seal \& Protect), a benzalconium containing desensitizer (Micro Prime), a fluoride containing prophilaxy paste (Sultan Desensitizer), two fluoride containing varnishes (Cavity Shealth and Ultra EZ), and a dentin bonding primer (All Bond).

Methods: The test materials were inserted in the wells of Muller Hinton agar plates inoculated with Streptococcus mutans, Streptococcus salivarious, Staphylococcus aureus, Streptococcus faecalis and Pseudomonas aeruginosa. The diameters of the inhibition zones produced around the materials were measured after $24 \mathrm{~h}$ of incubation. The results were analyzed by the Kruskal Wallis one way ANOVA and the Mann-Whitney tests at a significance level of $P<.05$.

Results: Micro Prime Desensitizer containing benzalkonium chloride had the highest antibacterial effectiveness compared to other desensitizers used in this study. In addition, triclosan containing Seal \& Protect and acidic components containing All Bond showed very high antibacterial efficacy. On the other hand, fluoride within both varnishes had little antibacterial effectiveness. However a fluoride component in a paste (Sultan Desensitizer) showed very high bactericidal effect.

Conclusions: All desensitizers except fluoride varnishes showed various degrees of antibacterial effect against the bacteria tested in this study. If antibacterial effect is also required from the desensitizers' clinicians should avoid use of varnishes. (Eur J Dent 2008;2:43-47)

Key words: Desensitizers; Desensitizing products; Antibacterial; Bactericidal effectiveness.

\section{INTRODUCTION}

Using scanning electron microscopic and light microscopic techniques, Adriaens et $\mathrm{al}^{1}$

a Assoc. Prof., Selcuk University, Faculty of Dentistry, Department of Periodontology.

b Assoc. Prof., Selcuk University, Faculty of Dentistry, Department of Conservative Dentistry.

Assoc. Prof., Selcuk University, Faculty of Veterinary, Department of Microbiology.

d Assist. Prof., Erciyes University, Faculty of Dentistry, Deparment of Operative Dentistry.

- Corresponding Author: Abdulkadir Sengun, Selcuk Universitesi, Dishekimligi Fakültesi, Dis Hastalıkları ve Tedavisi Anabilim Dali, Konya, Turkey. Phone: 00903322231245

Fax: 00903322410062

E-mail: asengundaselcuk.edu.tr demonstrated bacteria invading the radicular cementum and the dentinal tubules of the radicular dentin of periodontally diseased, caries-free human teeth. It has been reported that periodontal diseases, periodontal treatment, such as root planing or surgery and over-vigorous tooth brushing can cause gingival recession., ${ }^{2,3}$ Many authors claimed that such recession may account for the high prevalence of cervical dentin sensitivity (CDS) in periodontal patients. ${ }^{3,4}$ Furthermore, it is not known if hypersensitivity in the periodontal patients is true CDS or due to some underlying pathological process such as bacterial penetration into the dentinal tubules during the disease process. ${ }^{5}$ 
Periodontal treatment often results in the removal of the cementum and it has been claimed to be a factor in the occurrence of hypersensitive dentin and bacterial invasion to dentinal tubules. ${ }^{6-8}$ It has been suggested that bacteria and bacterial toxins, which are present in the diseased periodontium, can reach the pulp by way of lateral and/or accessory canals ${ }^{8,9}$ and dentinal tubules. ${ }^{10,11}$ It has been demonstrated that bacteria can invade open dentinal tubules and reach the pulp ${ }^{12}$ and that bacterial products, when applied to exposed dentin are capable of initiating inflammatory reactions in the underlying pulp. ${ }^{13}$

Most of recently developed desensitizers are considered to contribute to better clinical results by reducing the rate of the cervical dentin sensitivity. ${ }^{14,15}$ However, little is known about their antibacterial effects. ${ }^{14}$ This study assessed the antibacterial activity of various desensitizers available on the market against some bacteria found in dental plaque by Muller Hinton agar well method.

\section{MATERIALS AND METHODS}

In this study, a benzalconium containing product (Micro Prime), a triclosan containing product (Seal \& Protect), a dentin bonding primer (All Bond), a fluoride containing prophylaxis paste (Sultan Desensitizer) and two fluoride containing varnishes (Cavity Shealth and Ultra EZ) were used (Table 1). The antibacterial efficacy of each material was evaluated against the following bacteria: Streptococcus mutans (NCTC 10449); Streptococcus salivarious (RSKK 606); Staphylococcus aureus (ATCC 6538); Streptococcus faecalis (RSKK 97008); and Pseudomonas aeruginoza (ATCC 27853).

The study was performed on Muller Hinton Agar by Agar well Technique. The agar was evenly distributed over the surface of $15 \mathrm{~cm}$-in-diameter Petri dishes to a thickness of $5 \mathrm{~mm}$. Standard wells with a diameter of $6.0 \mathrm{~mm}$ were punched into the agar with the blunt end of a Pasteur pipette. Approximately $0.5 \mathrm{ml}$ suspensions of bacteria were swabbed over the surface of the agar plates. The concentrations of bacterial suspensions (CFU) were $2 \times 10^{7} \mathrm{~S}$. mutans, $6 \times 10^{8} \mathrm{~S}$. salivarious, $5 \times 10^{9} \mathrm{~S}$. aureus, $2 \times 10^{8} \mathrm{~S}$. faecalis, and $1.6 \times 10^{8} \mathrm{P}$. aeruginoza bacteria/ml, respectively. Each material was inserted into the wells with its own sterile applicator under a laminar flow. The agar plates were incubated at $37^{\circ} \mathrm{C}$ for $48 \mathrm{~h}$. The diameters of the inhibition zones around the materials were measured in millimeter ( $\mathrm{mm}$ ) (Figure 1). The test was repeated 12 times for each material.

\section{Statistical analysis}

The results of 12 measurements were averaged and these values were subjected to Kruskal wallis one way ANOVA and Mann Whitney test at a significance level of $P<.05$ for the comparison of the products.

\section{RESULTS}

Table 2 shows the mean values of the inhibition

Table 1. Active ingredients and manufacturer information of the test agents.

\begin{tabular}{|c|c|c|}
\hline Materials & Active ingredients & Manufacturers \\
\hline Micro PrimeTM (Lot 1424) & Benzethonium chloride and HEMA. & Danville Engineering Inc., CA, USA, \\
\hline & $\begin{array}{l}\text { Di and trimethacrylate resins, } \\
\text { PENTA, Functionalised amorphous }\end{array}$ & \\
\hline Seal ProtectR (Lot 0204001212) & $\begin{array}{c}\text { sicila, Photoinitators, Butylated } \\
\text { hydroxytoluence, Cetilamide } \\
\text { hydrofluoride, Triclosan, Acetone }\end{array}$ & Dentsply DeTrey, Germany \\
\hline All-BondR (Lot 0200001582-80) & $\begin{array}{l}\mathrm{N} \text {-tolyglycin-glycidyl methacrylate and } \\
\text { biphenyl dimethacrylate }\end{array}$ & Bisco Dental Products, IL, USA \\
\hline Sultan Desensitiser (Lot 23720) & Sodium fluoride, Kaolin, Glycerine & Sultan Chemists Englewood NJ \\
\hline Cavity ShieldTM (Lot 008 04) & Unit-dosed 5\% NaF Varnish & $\begin{array}{c}\text { OMNII Oral Pharmaceuticals FL, } \\
\text { USA }\end{array}$ \\
\hline UltraEZTM (Lot E044) & $\begin{array}{l}\text { Potassium Nitrate } \\
\text { Fluoride lon }\end{array}$ & Ultradent Products, Inc.Utah, USA \\
\hline
\end{tabular}


zones produced by each material tested. Micro Prime (MP) produced varying degrees of inhibitory effectiveness on the test bacteria. S. mutans and $P$. aeruginosa displayed a significantly lower resistance to MP than $S$. salivarious, $S$. faecalis and S. aureus respectively $(\mathrm{P}<.05)$. Seal \& Protect $(\mathrm{SP})$ showed the highest antibacterial effectiveness against $S$. aureus. SP produced the second highest antibacterial effectiveness against $P$. aeruginosa $(P<.05)$. Antibacterial effectiveness of SP against S. faecalis, S. mutans, and S. salivarious was not statistically different (P>.05). All Bond Primer showed its highest antibacterial effectiveness against $S$. faecalis and $P$. aeruginosa $(\mathrm{P}<.05)$. Sultan demonstrated significant antibacterial effectiveness against all test bacteria with $S$. mutans being the least inhibited $(P<.05)$. Among the materials tested, no inhibition zones were noted for Cavity Sheld and UltraEZ (P>.05).

\section{DISCUSSION}

Antibacterial effectiveness shown by the dental materials in some studies was related to either their $\mathrm{pH}$ or their chemical composition. For example, current desensitizers

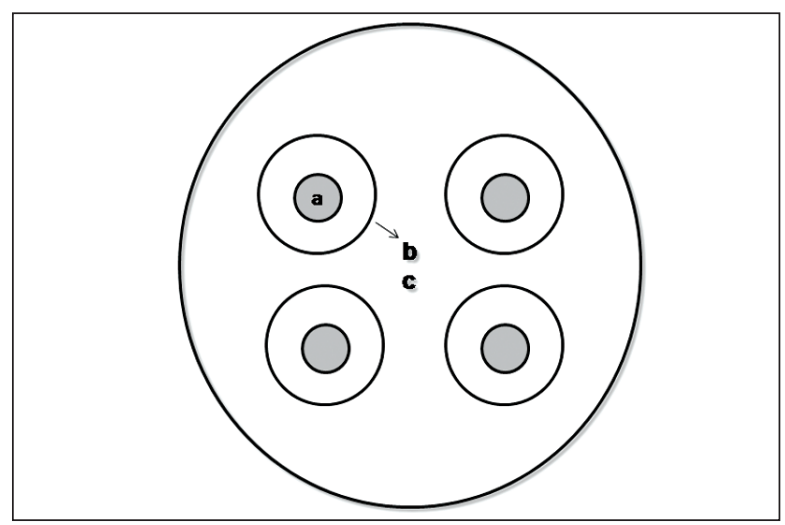

Figure 1. Diagram illustrating arrangement of the materials in wells in test petri. a: the materials in wells; $b$ : inhibition zone; c: agar.

Table 2. Diameters (mean $\pm S D)$ of antibacterial inhibition zones $(m m)(n=12)$

\begin{tabular}{l|c|c|c|c|c|c}
\cline { 2 - 7 } & Micro Prime & Seal \& Protect & All - Bond & Sultan & Cavity Shealth & UltraEZ \\
\hline S. mutans & $22.00 \pm 1.95 \mathrm{c}$ & $10.42 \pm 0.67 \mathrm{a}$ & $10.47 \pm 1.00 \mathrm{a}$ & $12.08 \pm .79 \mathrm{a}$ & $00.00 \pm 00.00 \mathrm{a}$ & $00.00 \pm 00.00 \mathrm{a}$ \\
P. aeruginosa & $21.92 \pm 0.90 \mathrm{c}$ & $15.25 \pm 1.14 \mathrm{~b}$ & $13.17 \pm 1.99 \mathrm{~b}$ & $14.00 \pm 1.48 \mathrm{~b}$ & $00.00 \pm 00.00 \mathrm{a}$ & $00.00 \pm 00.00 \mathrm{a}$ \\
S. aureus & $14.67 \pm 2.67 \mathrm{a}$ & $26.00 \pm 2.17 \mathrm{c}$ & $10.00 \pm 1.21 \mathrm{a}$ & $13.67 \pm 1.30 \mathrm{~b}$ & $00.00 \pm 00.00 \mathrm{a}$ & $00.00 \pm 00.00 \mathrm{a}$ \\
S. fecalis & $16.08 \pm 1.17 \mathrm{ab}$ & $11.17 \pm 2.37 \mathrm{a}$ & $14.42 \pm 2.28 \mathrm{~b}$ & $14.75 \pm 1.29 \mathrm{~b}$ & $00.00 \pm 00.00 \mathrm{a}$ & $00.00 \pm 00.00 \mathrm{a}$ \\
S. salivarius & $16.75 \pm 1.36 \mathrm{~b}$ & $10.00 \pm 0.85 \mathrm{a}$ & $12.92 \pm 2.19 \mathrm{~b}$ & $14.08 \pm 1.38 \mathrm{~b}$ & $00.00 \pm 00.00 \mathrm{a}$ & $00.00 \pm 00.00 \mathrm{a}$ \\
P (ANOVA) & 0.000 & 0.000 & 0.000 & 0.000 & 1.000 & 1.000 \\
\hline
\end{tabular}

The same letters at same column were not statistically different at $P>.05$ according to Mann Whitney $U$ test. include antibacterial components such as fluoride, triclosan, benzalkonium chloride, ethylene dianinetetraacetic acid, and glutaraldehyde. A dentin primer incorporating methacryloyloxydodecylpyridinium bromide was potentially able to kill any bacteria. ${ }^{16,17}$

The agar well technique test is an accepted method for initially differentiating antibacterial activity between materials. Accordingly, even if the material contains less diffusive antibacterial components the substantive antibacterial activity is available. It is difficult to evaluate the antibacterial effects of desensitizer by a single test and more than one method needs to be used for screening the materials. Furthermore, in order to speculate on clinical effects, in situ tests which simulate the clinical situation are indispensable.

Dental plaque is a host-associated biofilm. In this study, some microorganisms of dental plaque were used to determine antibacterial effectiveness of several desensitizers. Mutans streptococci are found in highest numberson teeth. These organisms have a strong affinity for hard surfaces, and do not usually appear in the mouth until after tooth eruption. $S$ salivarious is only a minor component of dental plaque and not considered a significant opportunistic pathogen. However, S. salivarious and $S$. mutans have been found to produce root caries. ${ }^{18}$ $S$. fecalis have been recovered in low numbers from several oral sites. Some strains can include dental caries in gnotobiotic rats while others have been isolated from infected root canals and from periodontal pockets. ${ }^{19}$ P. aeruginosa and $S$. aureus were colonized in pocket of the refractory chronic periodontitis patients. ${ }^{20} \mathrm{P}$. aeruginosa is resistant to tetracycline, penicillin $G$ and erythromycin. ${ }^{19}$ Antibacterial effectiveness of the desensitizers except for UltraEZ and Cavity Sheath used in this 
study was obtained against the bacteria above.

In a study by Emilson and Bergenholtz, ${ }^{21}$ it was suggested that the antibacterial nature of the Gluma and Denthesive cleanser might be related to the high content of ethylene dianinetetraacetic acid (EDTA) in the materials. The results of the present study also indicate that chemical composition of the desensitizers play an active role their antibacterial properties. Micro Prime (MP) desensitizer is used for desensitizing under dental cements or temporary, provisional, or final restorative materials, abrasions, cervical erosions, and preps. The antibacterial activity of MP desensitizer may be related to the chemical composition, which is benzalkonium chloride in nature. MP desensitizer had significant inhibitory effect on not only $S$. Mutans and $P$. aeruginosa but also on $S$. salivarious, $S$. faecalis. and $S$. aureus. This data supports the results of Duran and Sengun, ${ }^{14}$ who reported antibacterial effect of benzalkonium chloride containing Heath-Dent desensitizer.

Seal \& Protect desensitizer exhibited antibacterial zones that comparable in size with those of MP desensitizer. Its strong antibacterial activity might be due to antibacterialagent triclosan. The zones of bacterial inhibition produced with All Bond may be attributed to its ingredients.

Fluoride release is a factor in a materials' antibacterial effect; ${ }^{22}$ however, in this category of materials, UltraEZ and Cavity Sheath had no inhibition effect when compared with Sultan desensitizer in this study. In a study by Ekenback et $a_{1}{ }^{23}$ no statistically significant difference over time was found in S. Mutans, Lactobacilli or total Streptococci after treatment with the fluoride varnishes or tymol varnish. On the basis of the findings of Vermeersch et al, ${ }^{24}$ it was assumed that, in the set materials, fluoride ions might be firmly encapsulated by the resin matrix and that consequently its fluoride release rate into an aqueous environment might be small and slow. This may explain the ineffectiveness of fluoride containing varnishes in this study. However, this finding does not necessarily indicate that these materials have no antibacterial effectiveness. Moreover, release of fluoride from varnishes slowly in small amounts may be beneficial at the long term. Thus, relationship between release of fluoride and antibacterial effectiveness of varnishes should be an issue of future studies.

\section{CONCLUSIONS}

Micro Prime desensitizer containing benzalkonium chloride had the highest antibacterial effectiveness when compared with others in this study. In addition, Seal \& Protect which contains triclosan and All Bond which contains acidic components showed very high antibacterial efficacy. It can be deduced that fluoride within varnishes had little antibacterial effectiveness. However, a fluoride component in a paste (Sultan desensitizer) showed very high bactericidal efficacy. This study has demonstrated that currently marketed desensitizers have greatly in their ability to inhibit on growth of a variety of oral bacterial organisms in vitro. Fluoride containing varnishes should be avoided if immediate and high antibacterial activity is required. These experimental findings, however, only provide data that are useful for assessment of initial antibacterial effect. In vivo models that will account for many of the variables should be sought.

\section{ACKNOWLEDGMENTS}

The authors thank to Prof. Dr. Said Bodur for statistical analyzes and to Dr Serdar Usumez for English checking and Prof. Dr. Osman Erganis for microbiological laboratory helping.

\section{REFERENCES}

1. Adriaens PA, Edwards CA, De Boever JA, Loesche WJ. Ultrastructural observations on bacterial invasion in cementum and radicular dentin of periodontally diseased human teeth. J Periodontol 1988;59:493-503.

2. Watson PJ. Gingival recession. J Dent 1984;12:29-35.

3. Chabanski MB, Gillam DG, Bulman JS, Newman HN. Clinical evaluation of cervical dentine sensitivity in a population of patients referred to a specialist periodontology department: a pilot study. J Oral Rehabil 1997;24:666-672.

4. Fischer C, Fischer RG, Wennberg A. Prevalence and distribution of cervical dentine hypersensitivity in a population in Rio de Janeiro, Brazil. J Dent 1992;20:272276.

5. Adriaens PA, De Boever JA, Loesche WJ. Bacterial invasion in root cementum and radicular dentin of periodontally diseased teeth in humans. A reservoir of periodontopathic bacteria. J Periodontol 1988;59:222-230.

6. Hahn CL, Best AM, Tew JG. Cytokine induction by Streptococcus mutans and pulpal pathogenesis. Infect Immun 2000;68:6785-6789. 
7. Peters LB, Wesselink PR, Moorer WR. Penetration of bacteria in bovine root dentine in vitro. Int Endod $J$ 2000;33:28-36.

8. Love RM. The effect of tissue molecules on bacterial invasion of dentine. Oral Microbiol Immunol 2002;17:32-37.

9. Langeland K, Rodrigues H, Dowden W. Periodontal disease, bacteria, and pulpal histopathology. Oral Surg Oral Med Oral Pathol 1974;37:257-270.

10. Perez F, Calas P, de Falguerolles A, Maurette A. Migration of a Streptococcus sanguis strain through the root dentinal tubules. J Endod 1993;19:297-301.

11. Bergenholtz G, Lindhe J. Effect of experimentally induced marginal periodontitis and periodontal scaling on the dental pulp. J Clin Periodontol 1978;5:59-73.

12. Olgart L, Brannstrom M, Johnson G. Invasion of bacteria into dentinal tubules. Experiments in vivo and in vitro. Acta Odontol Scand 1974;32:61-70.

13. Bergenholtz G. Effect of bacterial products on inflammatory reactions in the dental pulp. Scand J Dent Res 1977;85:122129.

14. Duran I, Sengun A. The long-term effectiveness of five current desensitizing products on cervical dentine sensitivity. J Oral Rehabil 2004;31:351-356.

15. Duran I, Sengun A, Yildirim T, Ozturk B. In vitro dentine permeability evaluation of HEMA-based (desensitizing) products using split-chamber model following in vivo application in the dog. J Oral Rehabil 2005;32:34-38.

16. Imazato S, Imai T, Ebisu S. Antibacterial activity of proprietary self-etching primers. Am J Dent 1998;11:106108.

17. Imazato S, Kinomoto Y, Tarumi H, Torii M, Russell RR McCabe JF. Incorporation of antibacterial monomer MDPB into dentin primer. J Dent Res 1997;76:768-772.

18. Beighton D, Lynch E. Comparison of selected microflora of plaque and underlying carious dentine associated with primary root caries lesions. Caries Res 1995;29:154-158.

19. Marsh P MM. Oral microbiology. Fourth ed. New Delhi Oxford, 1999.

20. Slots J, Rams TE. New views on periodontal microbiota in special patient categories. J Clin Periodontol 1991;18:411420.

21. Emilson CG, Bergenholtz G. Antibacterial activity of dentinal bonding agents. Quintessence Int 1993;24:511-515.

22. Herrera M, Castillo A, Baca P, Carrion P. Antibacterial activity of glass-ionomer restorative cements exposed to cavity-producing microorganisms. Oper Dent 1999;24:286291.

23. Ekenback SB, Linder LE, Lonnies H. Effect of four dental varnishes on the colonization of cariogenic bacteria on exposed sound root surfaces. Caries Res 2000;34:70-74.
24. Vermeersch G, Leloup G, Vreven J. Fluoride release from glass-ionomer cements, compomers and resin composites. J Oral Rehabil 2001;28:26-32. 